\title{
Climate Change Adaptation Considerations for Agriculture for North-East Iraq
}

\author{
Saleh A Wasimi ${ }^{1 *}$, Nahlah Abbas $^{1}$ and Nadhir Al Ansari ${ }^{2}$ \\ ${ }^{1}$ Central Queensland University, Australia \\ ${ }^{2}$ Geotechnical Engineering, Lulea University of Technology, Sweden
}

Received: 畊 April 30, 2018; Published: 盋 May 09, 2018

*Corresponding author: Saleh A Wasimi, School of Engineering \& Technology, Central Queensland University, Melbourne, Australia

\begin{abstract}
Analysis of climatic data of the last three decades reveals that there is a noticeable shift in climate and water resources regime of north-east Iraq. Analysis was done on the five major tributaries of Tigris River-Khabur, Greater Zab, Lesser Zab, Al-Adhiam and Diyala rivers. At first glance, the region appears to have plenty of freshwater, but due to high temporal and spatial variability combined with inadequate infrastructure, water scarcity is widespread. Agriculture is the primary user of freshwater, and therefore, any adverse effect on water availability will have far reaching consequences. For forecasting purposes, SWAT model was chosen for simulation and GCM ensembles were used for long-range forecasts. The paper explores how the population are adjusting to the shift in climate regime and what kinds of climate change adaptation measures are socio-culturally viable. The analysis framework featured separation of freshwater availability into blue and green waters, climate forecasts with a lead time of about half-a-century to 2049-2069 and about one-century to 2080-2099, and feedback from grass-root level of the government and focus groups as to how the population are adjusting and likely to adjust in the future to climate change.
\end{abstract}

Keywords: Climate change; Adaptation; Agriculture; Northeast iraq

\section{Introduction}

The north-east Iraq, which includes autonomous Kurdistan, is regarded to have adequate freshwater, but due to high spatial and temporal variability, and accessibility issues owing to lack of proper infrastructure, water scarcity is widespread in the region. Freshwater availability is of critical importance for food security, public health and environment protection in the region, but detailed information on water resources and water scarcity is very limited [1] to address these issues adequately. Adding to the complexity in addressing these issues is the need for conformity of strategies to the social and cultural norms and expectations. Nevertheless, some data exist in disperse and disparate sources, which hitherto have not been used in planning [2], but can be collated for a coherent and thorough assessment of water resources of the region. This study attempted to achieve that objective, and then, explored the implications in social-cultural context. The quantity and quality of water resources in a basin is impacted by a multitude of factors such as precipitation and other meteorological variables, vegetation and other land cover, natural calamities such as hurricanes and earthquakes, and induced catastrophes such as bushfires. Changes in the quantity and quality of water can also occur with changes in population, climate and land use with alteration in supply and demand. Climate change has the potential to impact the hydrological cycle through the alteration of evapo transpiration and precipitation [3]. Changes also can be unprecedented because the water system could be vulnerable to climate change outside the range of historical events [4].

Falkenmark [5] first introduced the concept of blue water and green water. Blue water is water which humans can directly access such as stream flow and groundwater. Green water is water which humans cannot directly access such as evapo transpiration and soil moisture but it is useful for vegetation and agriculture. The blue/ green water notion has provided fresh ideas and new methodologies 
for water resources management in several regions especially in arid and semi-arid regions where water stress is severe due mainly to increased socioeconomic development and population growth. Blue/green concept can assist in supporting sustainable and equitable water resources management Jansson 1999. In this study SWAT model was chosen to simulate blue/green water due to its popularity, it has been widely used in varied physiographic regions and in various parts of the world [6,7]. SWAT is a physics-based distributed model well recognized for the analysis of the impacts of land management practices on water, sediment, agriculture, and non-point pollution in large complex watersheds [8]. Furthermore, SWAT model is capable of assessing the impacts of climate change on hydrological and biochemical cycles on a long term basis [9]. As is usually done, the impacts of climate change for the long-term has been assessed in this study by making forecasts through General Circulation Models (GCMs).

IPCC in its Fifth Assessment Report envisioned four Representative Concentration Pathways (RCPs) of future greenhouse gas concentrations, which replaces the SRES proposed by IPCC in its Third Assessment Report. For brevity, this study presents results from three RCPs - low (RCP2.6) which assumes sustained net negative anthropogenic GHG emissions after 2070, medium (RCP4.5) which assumes stabilization without overshoot to $4.5 \mathrm{~W} / \mathrm{m}^{2}$ radiative forcing after 2100 , and high (RCP8.5) which assumes continued anthropogenic GHG emissions. Coupled Model Inter comparison Project 5 (CMIP5) uses a number of sophisticated
GCMs for climate forecasts. In this study six GCMs, namely CCSM4, MIROC-ECM, GFDL-CM2.1, MRI-CGCM3, CNRM-CM3, and IPSLCM5A-LR were selected for ensemble climate change projections in north-east Iraq. The projected temperatures and precipitation were downscaled by BCSD method Maurer 2014. After we analysed the historical data and projected future climatic conditions and availability of water resources, we sought feedback from General Managers of Water Authority and focus groups on how the local population are currently adjusting to already manifest climate change, and how they are likely to adjust to the projected climate change in the future. A General Manager in the Ministry of Water Resources heads each basin who is assisted by engineers, technicians and water monitors.

\section{Study Area}

Tigris River has five major tributaries namely Khabur, Greater Zab, Lesser Zab, Al-Adhiam and Diyala Rivers (Figure 1). These tributaries are located in the left bank of the Tigris River between latitudes $33.20 \mathrm{~N}$ and $37.30 \mathrm{~N}$ and longitudes $42.90 \mathrm{E}$ and $46.90 \mathrm{E}$ and have significant contributions to Tigris flow. These tributaries are shared between Iraq and Turkey or Iraq and Iran except AlAdhiam River. The region is mountainous with many springs in the north and east and changes to flat terrain in the south and west. The mountainous areas generally get higher proportion of precipitation with generally typical near-natural nival regime. The characteristics of the basin of each tributary are summarized in Table 1.

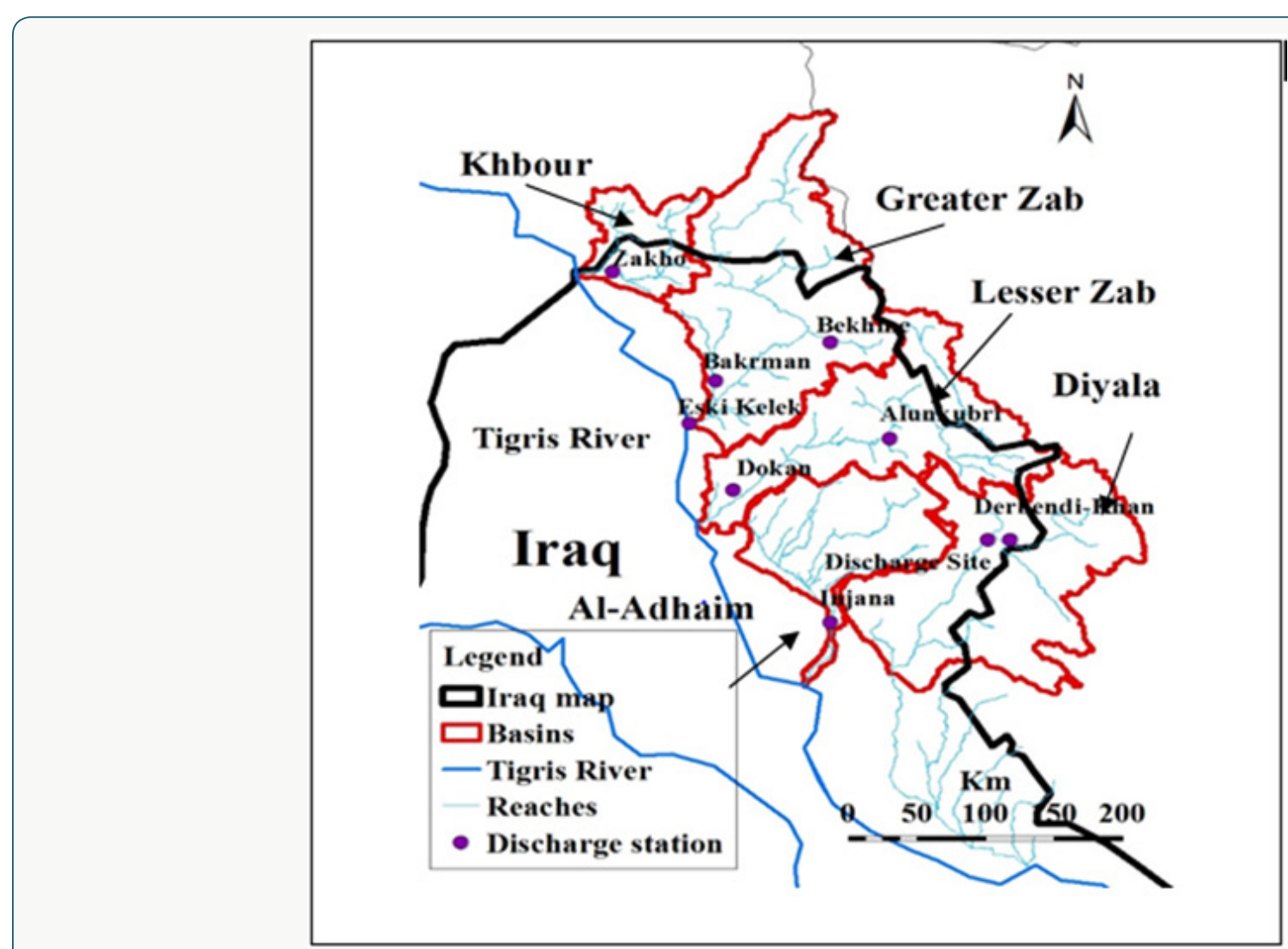

Figure 1: Location map of the study area. 
Table 1: Description of the basins of the five tributaries of Tigris River.

\begin{tabular}{|c|c|c|c|c|c|}
\hline River & Khabour & Greater Zab & Lesser Zab & Al-Adhaim & Diyala \\
\hline Basin area $(\mathrm{Km} 2)$ & 6143 & 26473 & 15600 & 13,000 & 33240 \\
\hline Basin area shares (\%) & $\begin{array}{c}\text { Iraq } 43 \% \\
\text { Turkey } 57 \%\end{array}$ & $\begin{array}{c}\text { Iraq } 65 \% \\
\text { Turkey 35\% }\end{array}$ & $\begin{array}{l}\text { Iraq } 80 \% \\
\text { Iran } 20 \%\end{array}$ & Iraq 100\% & $\begin{array}{l}\text { Iraq } 75 \% \\
\text { Iran } 25 \%\end{array}$ \\
\hline River length (Km) & $181 \mathrm{~km}$ & $462 \mathrm{~km}$ & $302 \mathrm{~km}$ & 230 & $574 \mathrm{~km}$ \\
\hline $\begin{array}{l}\text { Maximum annual flow } \\
\text { (BCM) }\end{array}$ & 4.3 & 23.6 & 15.1 & 1.2 & 14.4 \\
\hline $\begin{array}{l}\text { Minimum annual flow } \\
\text { (BCM) }\end{array}$ & 0.9 & 3.7 & 1.7 & 0.4 & 1.2 \\
\hline $\begin{array}{l}\text { Mean annual flow } \\
\text { (BCM) }\end{array}$ & 2 & 12.7 & 7.8 & 0.8 & 4.6 \\
\hline Dams & Unregulated to date & Unregulated to date & 2 & 1 & 3 \\
\hline
\end{tabular}

\section{Impacts of Climate Change}

SWAT model was used for hydrologic simulation and GCMs were used for climate forecasts. Basic data requirements for SWAT included digital elevation model (DEM), land use map, soil map, weather data, and discharge data. DEM was extracted from ASTER Global Digital Elevation Model (ASTERGDM) with a 30 meter grid and $1 \times 1$ degree tiles (http://gdem.ersdac.jspacesystems.or.jp/ tile_list.jsp). The land cover map was obtained from the European Environment Agency (http://www.eea.europa.eu/data-and-maps/ data/global-land-cover-250m) with a 250 meter grid raster for the year 2000. The soil map was collected from the global soil map of the Food and Agriculture Organization of the United Nations (FAO 1995). Weather data which included daily precipitation,
0.5 hourly precipitations, maximum and minimum temperatures were obtained from the Iraq's Bureau of Meteorology. Monthly stream flow data were collected from the Iraqi Ministry of Water Resources/National Water Centre. To evaluate the performance of SWAT, the sequential uncertainty fitting algorithm application (SUFI-2) embedded in the SWAT-CUP package [10] was used. Figure 2 captures the decade wise changes in precipitation for the past three decades. It is evident from the figures that water availability is decreasing with time. This study considers the period 19802010 as the baseline period for comparisons with future scenarios. Figure 3 captures the changes which are expected in the future from GCM outputs fed into SWAT - outputs from SWAT consisting of 320 HRUs for simulation.

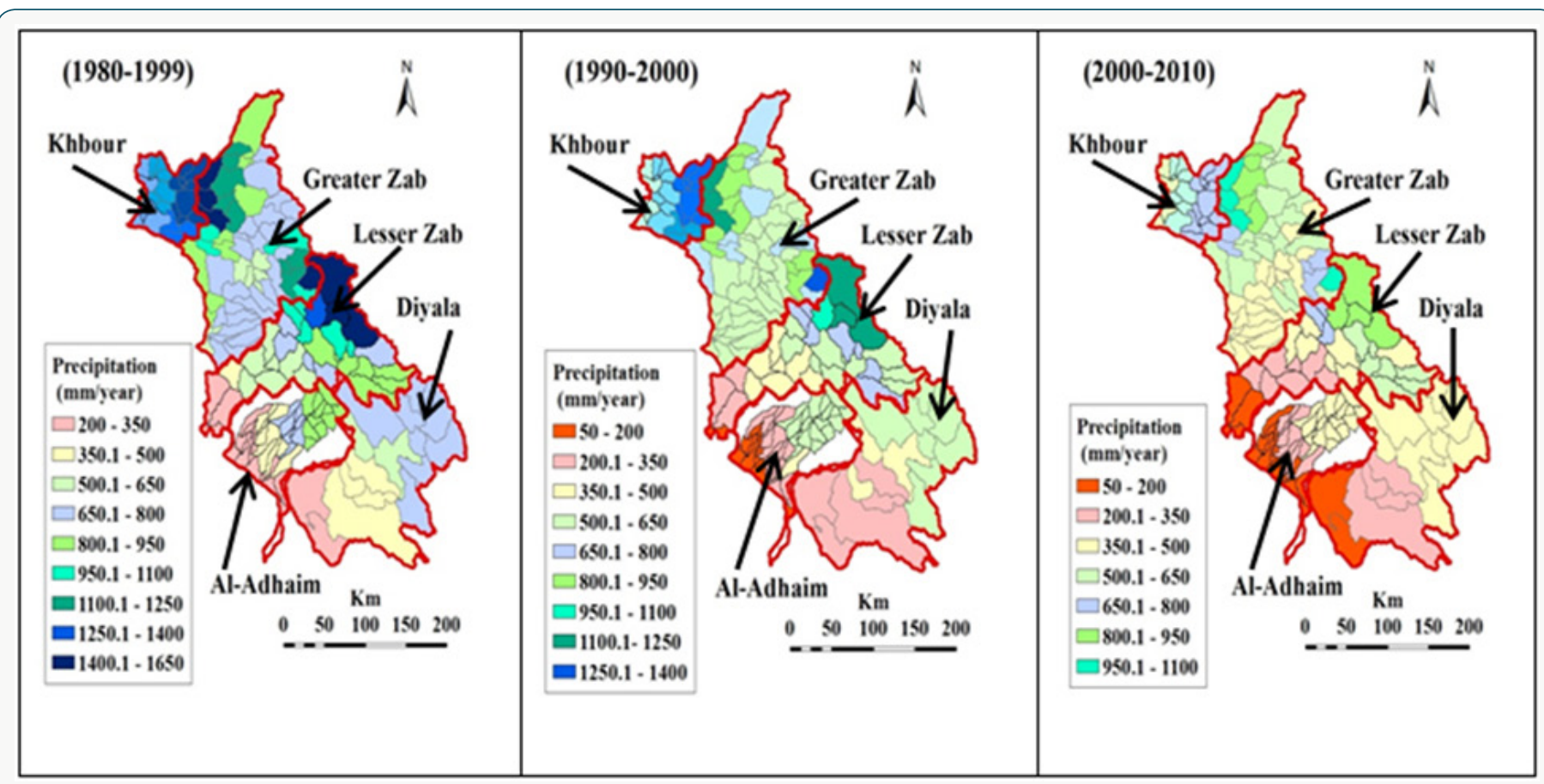

Figure 2: Spatial distribution of precipitation in Northeast Iraq. 


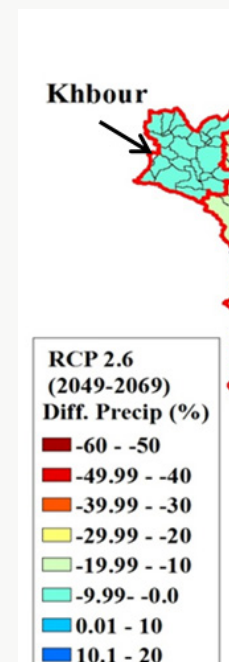

- 10.1 - 20

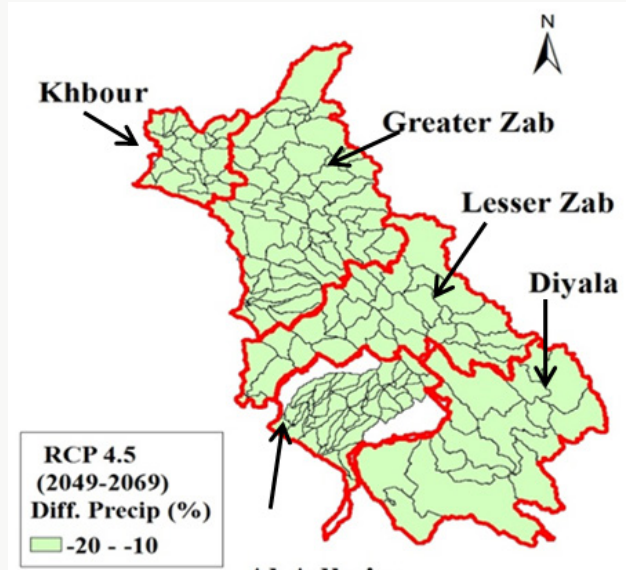

Al-Adhaim
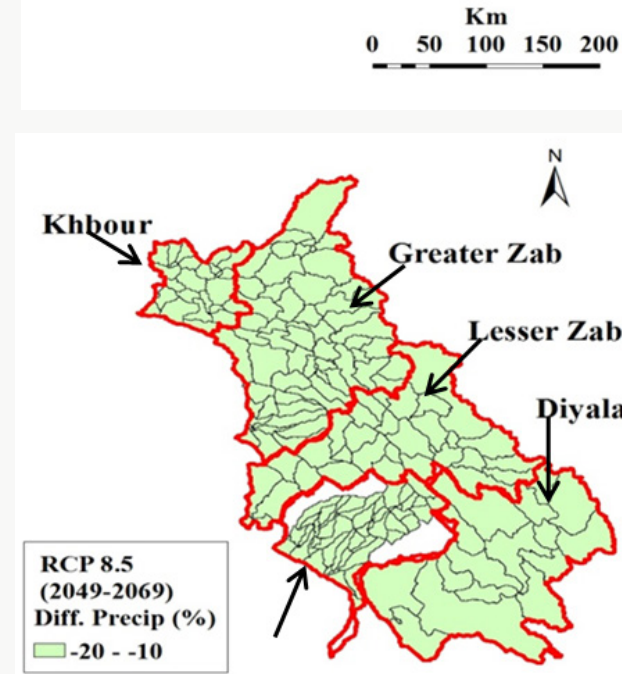

Al-Adhaim

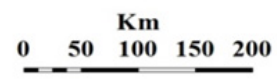

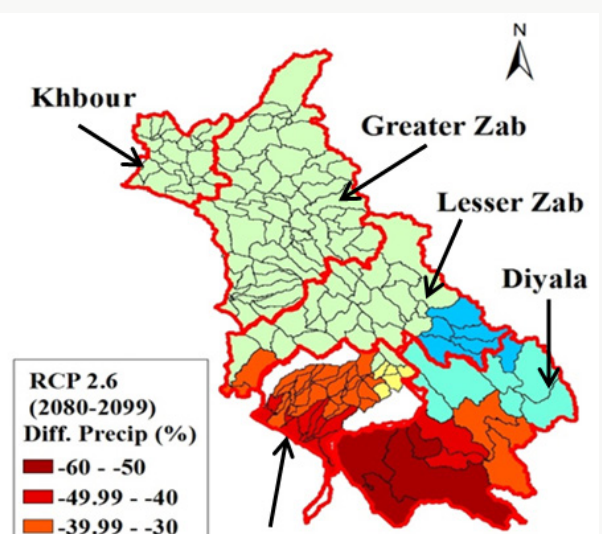

Al-Adhaim
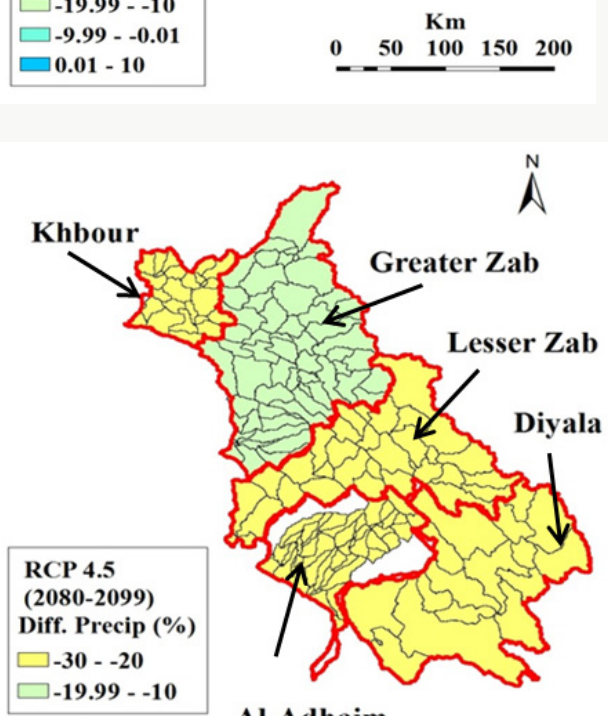

Al-Adhaim
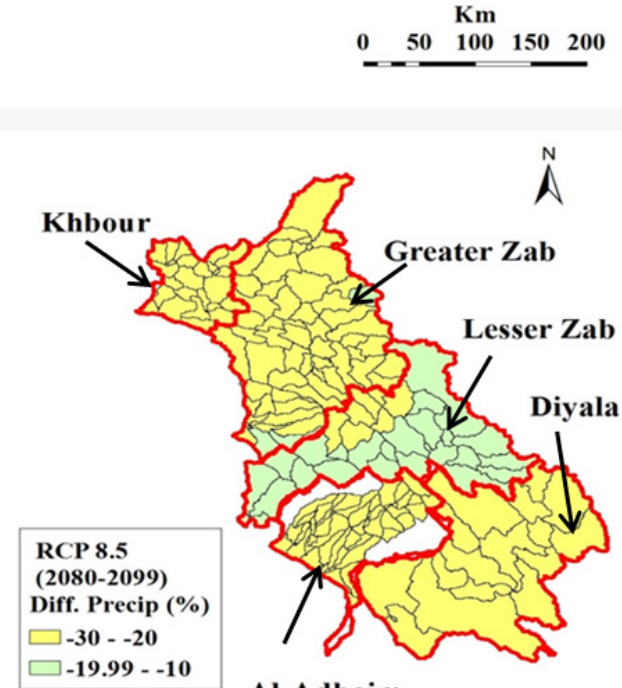

Al-Adhaim

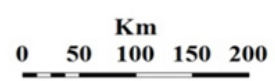

Figure 3: The impacts of climate change on the precipitation of the five basins (a) Anomaly based on scenario RCP 2.6 for the period 2049-2069, (b) Anomaly based on RCP 2.6 for 2080-2099, (c) Anomaly based on RCP 4.5 for 2049-2069, (d) Anomaly based on RCP 4.5 for 2080-2099, (e) Anomaly based on RCP 8.5 for 2049-2069, and (f) Anomaly based on RCP 8.5 for 2080-2099. 


\section{Climate Change Adaptation}

Although climate change is a physical process linking with alterations in climatic variables, it impacts and also is impacted by social processes associated with the way society evolves over time. Climate change has impacts on social, economic, and environmental systems and forms scenarios for food, water, and health security [11]. The capability of mitigating and adapting to climate change influences is dependent on proactive measures adopted by different socioeconomic groups living in differentiated geographical circumstances [12]. Climate change intensifies the vulnerability of the society. It leads to enhanced water scarcity, exposure to diseases and undermining of growth opportunities. The impacts of climate change in northeast of Iraq will vary geographically. The south part which includes Diyala and Al-Adhiam are projected to be most impacted by droughts and shortened growing seasons. Extreme droughts have categorized that region in the last three decades. Severe drought has caused a reduction in agricultural production especially in the areas of rain-fed crop, which resulted in an observed reduction in farmers' income. The social dimension, which influences physical and economic dimensions, mainly boosts vulnerability to climate change. In light of the sharp decline in oil prices and the increase in terrorist operations which have led to the deterioration of the economy, institutional structures, and individual capabilities Iraq is unable to manage the current climate variability and will struggle with projected changes due to insufficient financial resources available for adaptation and mitigation.

Vulnerability in the context of climate change has three components which are exposure, sensitivity and adaptive capacity [13]. For example, agricultural vulnerability to climate change can be described in terms of exposure to increased temperatures, decreased rainfall and thus reduction in water resources. The sensitivity of crop yields can be described through how sensitive the crops are to these changes. Adaptive capacity is defined as the ability of the farmers to adapt to the effects of this exposure and sensitivity by, for example, growing crop varieties that are more drought-resistant. Recent studies stress the significance of socioeconomic factors for the adaptive capacity of a system, especially underlining the essential role of institutions, governance and management in determining the ability to adapt to climate change [14]. The adaptive capacity of any system is fundamentally shaped by human actions and, it influences both the biophysical and social elements of a system. Generally, agricultural adaptation includes two forms of amendments in agricultural production systems. The first strategy is enhanced agricultural diversification through, for example, using drought tolerant varieties to temperature stresses. The second strategy emphasizes crop management practices, for instance, managing critical crop growth stages by not coinciding with very harsh climatic conditions such as mid-season droughts. According to Orindi [15], shifting the length of the growing period and changing planting and harvesting dates are among the common crop management practices that are used in agricultural adaptation to climate change.

For this study, focus groups of farmers were formed organized by general managers of each catchment. The discussion thread centred on farmers' perception of climate change and the adaptation measures they already have or would take to respond to the negative impacts of climate change. From their answers it became evident that planting trees, crop diversification, changing planting dates, and soil conservation are the major adaptation strategies that farmers recognize as appropriate for rain-fed agriculture. Planting trees - This strategy includes growing trees in the farm to serve as shade against severe temperature. Growing trees and a forestation enhance agricultural productivity, where it often contributes to climate change mitigation through enhanced carbon sequestration [16]. Crop diversification - Farmers grow different crop varieties that have ability to survive in adverse climatic conditions. In addition, growers plant early ripening crop varieties and grow drought tolerant crops and crops that are resistant to temperature stresses. These are significant forms of insurance against rainfall fluctuations [15]. Furthermore, planting diverse crop varieties in the same field or various plots with different crops moderates the risk of whole crop failure because different crops are influenced differently by climate events and thereby gives some minimum assured returns for livelihood security $[17,18]$.

Changing planting dates - Early and late planting is another strategy to adapt to climate change. This strategy enables farmers to protect sensitive growth stages to ensure that these critical stages do not coincide with severe climatic conditions. Soil conservation - Soil conservation practices are to increase productivity on-farm [19-23]. Decreasing rainfall and increasing prolonged periods of drought, due to climate change, are highly likely to reduce crops. Increasing soil health and fertility leads to increase crop productivity, thus serve to moderate the impact of climate change on agricultural productivity [24,25].

\section{Conclusion}

Northeast Iraq has witnessed declining water availability in the past few decades and the model predictions are that the situation will get worse in the future. These findings may have far reaching consequences because a large area already suffers from per capita water scarcity. Already a majority of the farmers in the focus groups have observed that the climate has become hotter and drier, and the availability of water has decreased significantly especially in the southern region. This fits with the mathematical model inferences. The good part is that most farmers are willing to adopt modern methods to deal with climate change. A common theme that emanated from the focus groups is that a large proportion of farmers are poor and they cannot sustain consecutive crop losses or very low yields. Some of them have quit farming and have moved into or seeking alternative livelihood. For the stability of the social fabric, it is desirable to entice those people back into farming and 
for that to happen, financial support would be necessary. However, a large portion of the population is Muslim, and therefore preferably, finance source, destination and transaction process should be free from interest (riba), gambling (maysir), uncertainty (gharar), coercion (ikrah), and forbidden (haram) - directives of Islamic law.

\section{References}

1. UN ESCWA, BGR (2013) United Nations Economic and Social Commission for Western Asia; Federal Institute for Geosciences and Natural Resources. Inventory of Shared Water Resources in Western Asia. Beirut, Lebanon.

2. Al Ansari N, M Abdellatif, M Ezeelden, SS Ali, S Knutsson (2014) Climate Change and Future Long Term Trends of Rainfall at North East of Iraq Journal of Civil Engineering and Architecture 8(6): 790-805.

3. Xuan Z, NB Chang (2014) Modeling the climate-induced changes of lake ecosystem structure under the cascade impacts of hurricanes and droughts. Journal of Ecological Modelling 288: 79-93.

4. Borgomeo E, G Pflug, JW Hall, S Hochrainer Stigler (2015) Assessing Water Resource System Vulnerability to Unprecedented Hydrological Drought Using Copulas to Characterize Drought Duration and Deficit. Water Resources Research 51(11): 8927-8948.

5. Falkenmark M (1989) The Massive Water Scarcity now Threatening Africa: Why isn't it being Addressed?. Ambio 18(2): 111-118.

6. Sinnathamby S, Douglas Mankin KR, Craige C (2017) Field-scale calibration of crop-yield parameters in the Soil and Water Assessment Tool (SWAT). Agricultural Water Management 180: 61-69.

7. Wagena MB, Sommerlot A, Abiy AZ, Collic AS, Langan S, et al. (2016) Climate change in the Blue Nile Basin Ethiopia: implications for water resources and sediment transport. Climatic Change 139(2): 229-243.

8. Schuol J, K Abbaspour (2007) Using monthly weather statistics to generate daily data in a SWAT model application to West Africa. Journal of Ecological Modelling 201(3-4): 301-311.

9. Neitsch SL, JG Arnold, JR Kiniry, JR Williams (2005) Soil and Water Assessment Tool Theoretical Documentation. Grassland, Soil and Water Research Laboratory, Temple, Texas, USA.

10. Abbaspour KC, J Yang, I Maximov, R Siber, K Bogner, et al. (2007) Modelling Hydrology and Water Quality in the Pre-Alpine/Alpine Thur Watershed Using SWAT. Journal of Hydrology 333(2-4): 413-430.

11. Bryan E, TT Deressa, GA Gbetibouo, C Ringler (2009) Adaptation to climate change in Ethiopia and South Africa: options and constraints. Journal of Environmental Science \& Policy 12(4): 413-426.

12. Deressa TT, RM Hassan, C Ringler, T Alemu, M Yesuf (2009) Determinants of farmers' choice of adaptation methods to climate change in the Nile Basin of Ethiopia. Journal of Global environmental change 19(2): 248255.
13. Fellmann T (2012) The assessment of climate change-related vulnerability in the agricultural sector: reviewing conceptual frameworks. Building resilience for adaptation to climate change in the agriculture sector. FAO/OECD Workshop 23(37).

14. Adger WN, S Agrawala, MMQ Mirza, C Conde, K O Brien, et al. (2007) Assessment of adaptation practices, options, constraints and capacity. Climate Change 2007: Impacts, Adaptation and Vulnerability. Contribution of Working Group II to the Fourth Assessment Report of the Intergovernmental Panel on Climate Change. In ML Parry, OF Canziani, JP Palutikof, PJ van der Linden, CE Hanson, (Eds.), Cambridge University Press, Cambridge, UK, pp. 717-743.

15. Orindi V, S Eriksen (2005) Mainstreaming adaptation to climate change in the development process in Uganda. Ecopolicy series no. 15, Acts Press, Nairobi, Kenya.

16. Gebrehiwot T, A van der Veen (2013) Farm level adaptation to climate change: the case of farmer's in the Ethiopian Highlands. Journal of Environmental Management 52(1): 29-44.

17. Simon Hales (2007) Climate Change 2007: impacts, adaptation and vulnerability: contribution of Working Group II to the fourth assessment report of the Intergovernmental Panel on Climate Change, Cambridge University Press, USA.

18. Priestley CHB, RJ Taylor (1972) On the Assessment of Surface Heat Flux and Evaporation Using Large-Scale Parameters. Bulletin of American Meteorological Society 100(2): 81-92.

19. Raghavan SV, VM Tue, L Shie Yui (2014) Impact of Climate Change on Future Stream Flow in the Dakbla River Basin. Journal of Hydroinformatics 16(1): 231-244.

20. Rostamian R, A Jaleh, M Afyuni, SF Mousavi, M Heidarpour, et al. (2008) Application of a SWAT Model for Estimating Runoff and Sediment in Two Mountainous Basins in Central Iran. Hydrological Sciences Journal 53(5): 977-988.

21. Schilling KE, MK Jha, YK Zhang, PW Gassman, CF Wolter (2008) Impact of Land Use and Land Cover Change on the Water Balance of a Large Agricultural Watershed: Historical Effects and Future Directions. Water Resources Research 44(7): 1-12.

22. Schuol J, KC Abbaspour (2007) Using Monthly Weather Statistics to Generate Daily Data in a SWAT Model Application to West Africa. Ecological Modelling 201(3): 301-311.

23. Wu K, CA Johnston (2007) Hydrologic Response to Climatic Variability in a Great Lakes Watershed: A Case Study with the SWAT Model. Journal of Hydrology 337(1): 187-199.

24. Yang J, P Reichert, KC Abbaspour, J Xia, H Yang (2008) Comparing Uncertainty Analysis Techniques for a SWAT Application to the Chaohe Basin in China. Journal of Hydrology 358(1-2): 1-23.

25.Zhang X, YP Xu, G Fu (2014) Uncertainties in SWAT Extreme Flow Simulation under Climate Change. Journal of Hydrology 515(16): 205222. 
(C) (1) This work is licensed under Creative Commons Attribution 4.0 License

To Submit Your Article Click Here: Submit Article

DOI: 10.32474/CIACR.2018.02.000143

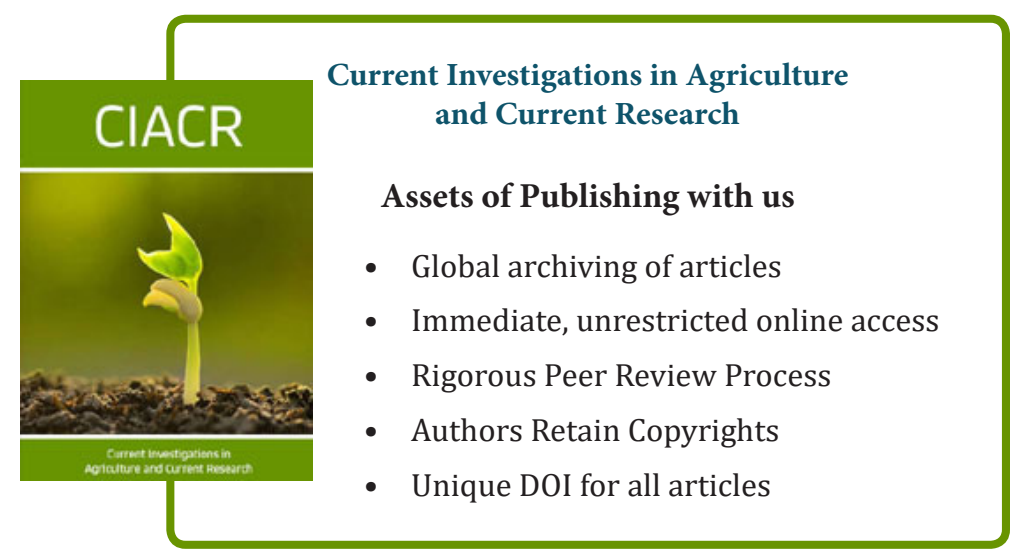

